\title{
Active and Reactive Power Control of Doubly Fed Induction Generator Wind Turbines to Answer Grid Codes Requirements
}

\author{
Mbarek Taleb and Mohamed Cherkaoui
}

\begin{abstract}
Recently, wind energy becomes one of important and promising sources of renewable energy despite its important fluctuations due to wind time varying nature. These fluctuations affect the power quality in the grid, mainly in term of frequency and voltage stability. Thus, Grid Managers are now dictating dynamic profiles for active and reactive powers that must be respected at the Point of Common Coupling (PCC) to make wind installations able to support the control of grid frequency and grid voltage.

In this paper, it is detailed one of the most important types of Wind Energy Conversion System (WECS) consisting on Turbine associated with Doubly Fed Induction Generator (DFIG). Vector control concept using stator flux orientation is adopted to allow independent control of active and reactive powers to answer easily Grid Codes requirements.

This work is limited to present the PI control with its direct and indirect approaches that are compared by using MATLAB-SIMULINK software. Except its limited robustness, PI Controller stays a simple and easy solution to control the power flow between WECS farms and electrical network. It should be noticed, however, that Indirect approach based on currents control gives better results in term of overshooting rates.

This work constitutes a good basis to implement any other PQ control strategy.
\end{abstract}

Index Terms-DFIG, variable speed wind turbine, power control, PI control, grid codes.

\section{INTRODUCTION}

Renewable energy sources such as solar, wind, sea energy (tidal and wave) and biomass emerged as a solution for global warming effect, population growth, fossil-fuel depletion and its insecure transportation.

Among all these alternative renewable sources, wind energy received a great interest and become the fastest growing energy by rising from $59 \mathrm{GW}$ on 2005 to $433 \mathrm{GW}$ on 2015 [1]. It is expected to reach $759 \mathrm{GW}$ by 2020 and $1600 \mathrm{GW}$ by 2030 supplying more than $20 \%$ of worldwide power [2].

The success of this energy is in part due to the fact that its cost has gone down by more than $80 \%$ since the early 1980 's [3]. Now, in many countries we can find offers at less than 4 cents even less than 3 cents in USA [3] and in Morocco [4].

While utility customers rapidly adopted renewable energies motivated by cost and environmental benefits, grid

Manuscript received May 5, 2017; revised August 7, 2017.

Mbarek Taleb and Mohamed Cherkaoui are with the Electrical Engineering Department of "Ecole Mohammadia d'Ingénieurs" (EMI), University Mohammed V, Agdal, Rabat 10000 Morocco (e-mail: taleb_bartex300915@yahoo.fr). managers are beginning to encounter various challenges related to intermittence and less forecasting accuracy of different patterns of renewable energies. In addition, aging electrical grid was originally configured to support just one-way power flow and was sized according to predictable demand. Today, a global shift in policy is helping to counter these issues. That is why transmission system operators (TSOs) in many countries are issuing grid codes to regulate the connection of power installations to the grids in order to maintain quality and stability.

In wind energy conversion systems, many topologies are used, but the most popular is the one that use DFIG for which stator is connected directly to the grid while the rotor is connected to grid through double bi-directional converters separated by a DC-Link [5] as shown in Fig. 1.



Fig. 1. Synoptic scheme of DFIG wind energy conversion system.

A variety of algorithms used in literature. From linear ones, basic PI is widely used followed by some sophisticated ones such as LQG (Linear Quadratic Gaussian) [6] and then by more special ones as ADRC (Active Disturbance Rejection Control) [7], [8]. Since last decade, these linear controllers started drastically giving way to nonlinear ones because of their limitations in front of WECS strong intrinsic nonlinearities and its parameters variations. Among these, the most popular are conventional (first order) Sliding Mode Controller (SMC) [9], [10], Adaptive Sliding Mode Controller (ASMC) [11] and some algorithms based on Artificial Intelligence (AI) such as Fuzzy Logic Controller (FLC) [12], Neuronal Network Controller (NNC) [13], [14], Genetic Algorithm (GA) [15] and Particle Swarm Optimization (PSO) [16], [17]. All these AI controllers need more computation time and then real time execution is compromised.

These algorithms are generally relatively complex and need some manually adjustments and then good experience to settle their parameters. They are still not mature for WECS domain. In contrast, PI controllers are easier and more appropriate for WECS and generally give better performances in steady states. Their performances are limited in transient regimes and their robustness is very weak. That is 
why they are frequently combined with other robust controllers as those mentioned above.

\section{MODELLING OF THE WIND TURBINE}

A part of Kinetic energy of the wind is captured by turbine blades according to a power coefficient, specific to each turbine and that is commonly approximated by the expression [18]:

$$
\begin{gathered}
C_{p}(\lambda, \beta)=C_{1}\left(\frac{C_{2}}{\lambda_{i}}-C_{3} \beta-C_{4}\right) \exp \left(-\frac{C_{5}}{\lambda_{i}}\right)+C_{6} \lambda \\
\frac{1}{\lambda_{i}}=\frac{1}{\lambda+0.08 \beta}-\frac{0.035}{1+\beta ?} \\
\left(c_{1}=0.5872, c_{2}=116, c_{3}=0.4, c_{4}=5, c_{5}=21, c_{6}=0.0085\right)
\end{gathered}
$$

$\beta$ is the blade pitch angle and $\lambda=\frac{R \omega_{t}}{v}$ is the tip speed ratio where $R$ and $\omega_{t}$ are respectively rotor radius and rotor speed of the turbine and $v$ the wind speed.

$C_{p}(\lambda, \beta)$ illustrated in Fig. 2 cannot exceed the Betz limit $C_{p_{-} \max }=16 / 27 \simeq 0.59$.

In our case $C_{p-o p t} \simeq 0.48$ obtained for $\beta=0$ and $\lambda=\lambda_{\text {opt }} \simeq 8$.

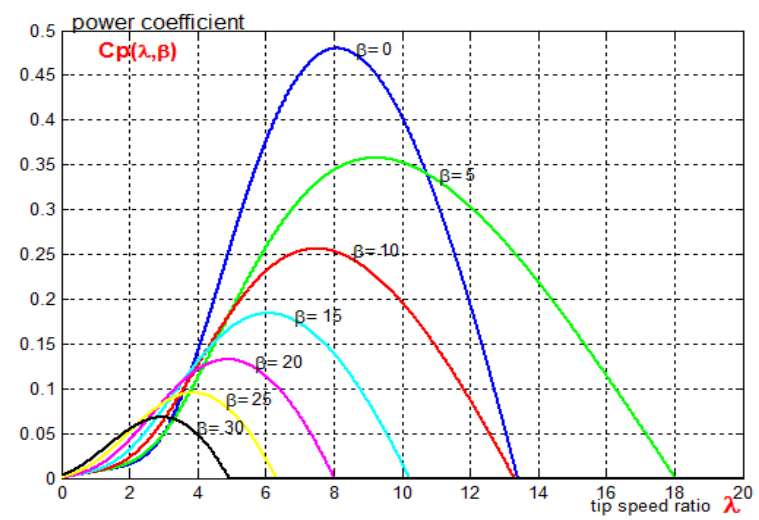

Fig. 2. Power Coefficient variation against $\lambda$ and $\beta$.

The popular approach called MPPT (Maximum Power Point Tracking) is widely used in WECS and it consists to adjust the Generator speed to capture the Maximum Power from the wind, for any wind speed $v$ as shown in Fig. 3.

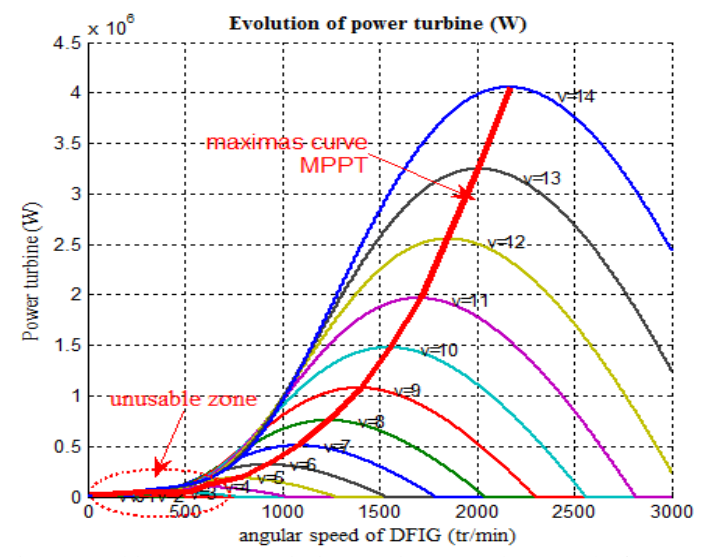

Fig. 3. Turbine Power variation against angular speed of DFIG.

But recently, because of important renewable energies integration, MPPT approach stays a particular case of the PQ control. In fact, new grid codes are dictating profiles for active and reactive powers to respect, in order to participate in maintaining power quality in the grids. Consequently, it is not allways possible to use MPPT strategy, unless if wind farm is provided of storage energy system.

We give here from [19] following examples:

- Canada grid codes request reactive power participation up to $50 \%$ of active power for absorption and up to $30 \%$ for production.

- German grid codes ask wind farms to reduce active power by $40 \%$ for each $1 \mathrm{~Hz}$ of extra elevation of frequency while reactive power must be able to vary from $-30 \%$ (absorption) to $+30 \%$ (production).

- Moroccan grid codes exige the ability to absorbe and to supply reactive power by $-30 \%$ and $+40 \%$ of rated active power respectively.

\section{Modelling OF THE DFIG}

The model of DEFIG in the $\mathrm{d}-\mathrm{q}$ Park reference frame rotating at synchronous speed $\omega_{s}$ is described as follow [20]:

$$
\begin{aligned}
& \left\{\begin{array}{l}
v_{s d}=R_{s} i_{s d}+\frac{d \phi_{s d}}{d t}-\omega_{s} \phi_{s q} \\
v_{s q}=R_{s} i_{s q}+\frac{d \phi_{s q}}{d t}+\omega_{s} \phi_{s d} \\
v_{r d}=R_{r} i_{r d}+\frac{d \phi_{r d}}{d t}-\omega_{r} \phi_{r q} \\
v_{r q}=R_{r} i_{r q}+\frac{d \phi_{r q}}{d t}+\omega_{r} \phi_{r d}
\end{array}\right. \\
& \text { with: }\left\{\begin{array}{l}
\phi_{s d}=L_{s} i_{s d}+M i_{r d} \\
\phi_{s q}=L_{s} i_{s q}+M i_{r q} \\
\phi_{r d}=L_{r} i_{r d}+M i_{s d} \\
\phi_{r q}=L_{r} i_{r q}+M i_{s q}
\end{array}\right.
\end{aligned}
$$

The active and reactive power at the stator side of DFIG are defined by:

$$
P_{s}=v_{s d} i_{s d}+v_{s q} i_{s q} \text { and } Q_{s}=v_{s q} i_{s d}-v_{s d} i_{s q}
$$

To simplify the equations, we opted for stator flux orientation in the $\mathrm{d}$-axis direction to obtain:

$$
\phi_{s d}=\phi_{s} \text { and } \phi_{s q}=0
$$

In addition, while resistance of the stator $R_{s}$ is neglected (that is legitimate for medium and large machines) and $\phi_{s}$ is supposed constant (steady grid), thus:

$$
\frac{d \phi_{s}}{d t}=0, v_{s d}=0, v_{s q}=v_{s}=\omega_{s} \phi_{s}
$$

It yields:

$$
\begin{aligned}
& v_{r d}=R_{r} i_{r d}+\sigma L_{r} \frac{d i_{r d}}{d t}-\omega_{r} \sigma L_{r} i_{r q}+\frac{M v_{s}}{L_{s}} \\
& v_{r q}=R_{r} i_{r q}+\sigma L_{r} \frac{d i_{r q}}{d t}+\omega_{r} \sigma L_{r} i_{r d}+\frac{g M v_{s}}{L_{s}}
\end{aligned}
$$

with: $\sigma=1-\frac{M^{2}}{L_{s} L_{r}}$ is leakage factor, and $g=\frac{\omega_{r}}{\omega_{s}}$ is the slip range. 
And by using (3), stator currents can be expressed according to rotor currents as follow:

$$
\begin{gathered}
i_{s d}=-\frac{M}{L_{s}} i_{r d}+\frac{v_{s}}{L_{s} \omega_{s}} \\
i_{s q}=-\frac{M}{L_{s}} i_{r q}
\end{gathered}
$$

Finally, from (4), we deduce the following simplified expressions of $P_{s}$ and $Q_{s}$ :

$$
\begin{gathered}
P_{s}=-\frac{M}{L_{s}} v_{s} i_{r q} \\
Q_{s}=-\frac{M}{L_{s}} v_{s} i_{r d}+\frac{v_{s}^{2}}{L_{s} \omega_{s}}
\end{gathered}
$$

It can be noticed that active power and reactive powers are independently controlled respectively by quadrature and direct rotor currents. Thus, it is easy to answer new grid codes requirements in term of PQ profiles.

The Fig. 4 shows the internal functional diagram of the DFIG in PQ control purpose.

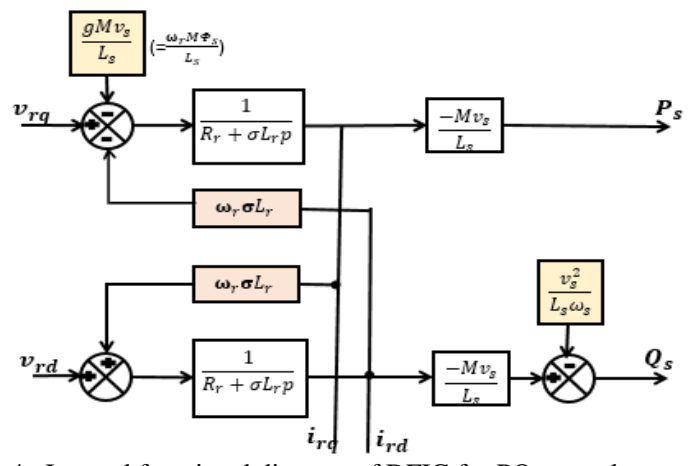

Fig. 4. Internal functional diagram of DFIG for PQ control purpose.

Currents and voltages are linked by same first order transfer function with a cross coupling that should be compensated as shown in Fig. 5.

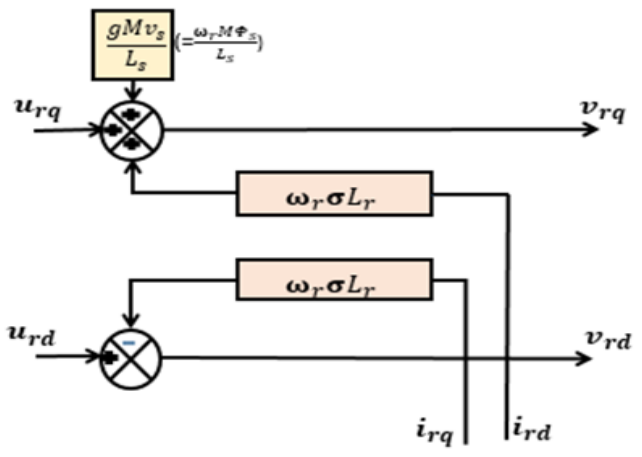

Fig. 5. Decoupling bloc.

The currents $i_{r d}$ et $i_{r q}$ are now linked to $u_{r d}$ and $u_{r q}$ through a first order function:

$$
H(p)=\frac{1}{R_{r}+\sigma L_{r} p}, i_{r d}=H(p) u_{r d}, i_{r q}=H(p) u_{r q}
$$

\section{PI CONTROL OF ACTIVE AND REACTIVE POWERS}

\section{A. Indirect PI Control}

According to equations (11) and (12), active and reactive powers can be controlled via rotor currents. That is why we call this approach indirect method.

The currents references are deducted as follow:

$$
\begin{gathered}
i_{r q_{-} r e f}=\left(-\frac{L_{s}}{M v_{s}}\right) \cdot P_{s_{-} r e f} \\
i_{r d_{-} r e f}=\left(-\frac{L_{s}}{M v_{s}}\right) \cdot\left(Q_{s_{-} r e f}-\frac{v_{s}^{2}}{L_{s} \omega_{s}}\right)
\end{gathered}
$$

The PI Controller expression is: $C_{i}(p)=K_{p i}+\frac{K_{i i}}{p}$.

With poles compensation approach, proportional and integral gains are expressed as follow:

$$
\left\{\begin{array}{l}
K_{p i}=\frac{3 \sigma L_{r}}{T_{r p i}} \\
K_{i i}=\frac{3 R_{r}}{T_{r p i}}
\end{array}\right.
$$

and where $T_{r p i}=3 \tau=\frac{3 \sigma L_{r}}{K_{p i}}$ is response time at $95 \%$ that we fix according to the global dynamic requested for the system. Synoptic scheme is shown in Fig. 6.

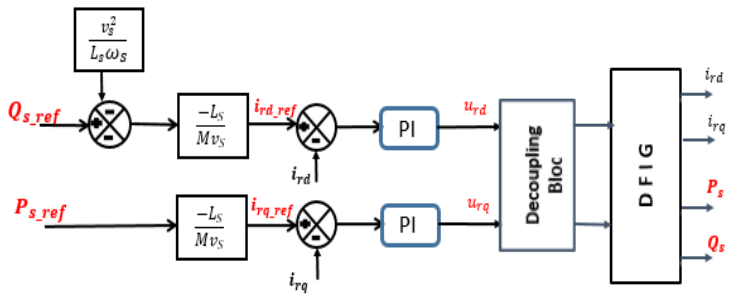

Fig. 6. Indirect PQ Control using PI

\section{B. Direct PI Control}

Using (8) and (9), active and reactive powers become:

$$
P_{s}=\frac{-\frac{M v_{s}}{L_{s}}}{R_{r}+\sigma L_{r} p} u_{r q} \text { and } Q_{s}=\frac{-\frac{M v_{s}}{L_{s}}}{R_{r}+\sigma L_{r} p} u_{r d}+\frac{v_{s}^{2}}{L_{s} \omega_{s}}
$$

Expression of $Q_{s}$ reveals the term $\frac{v_{s}^{2}}{L_{s} \omega_{s}}$ that should be compensated to have a behaviour of a first order system. Synoptic scheme is shown in Fig. 7.

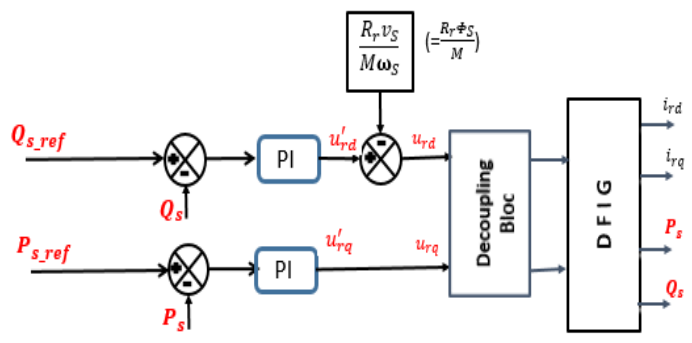

Fig. 7. Direct PQ Control using PI.

The expression of PI Controller is: $C_{d}(p)=K_{p d}+\frac{K_{i d}}{p}$ with

$$
\left\{\begin{array}{l}
K_{i d}=\frac{-3 R_{r} L_{s}}{M v_{s} T_{r p d}} \\
K_{p d}=\frac{-3 \sigma L_{s} L_{r}}{M v_{s} T_{r p d}}
\end{array}\right.
$$


and where $T_{r p d}=\frac{3 \sigma L_{r}}{M v_{s} K_{p d}}$ is response time at $95 \%$.

\section{Simulation and Comparison}

Simulation is made by hardly submitting the system to reference profiles of active and reactive power as illustrated in Fig. 8. In practice, variations of $P_{s_{-} \text {ref }}$ and $Q_{s_{-} \text {ref }}$ are not instantaneous but made according to defined ramps. Simulations results are given in Fig. 9 and Fig. 10 for indirect control and in Fig. 11 and Fig. 12 for direct control.

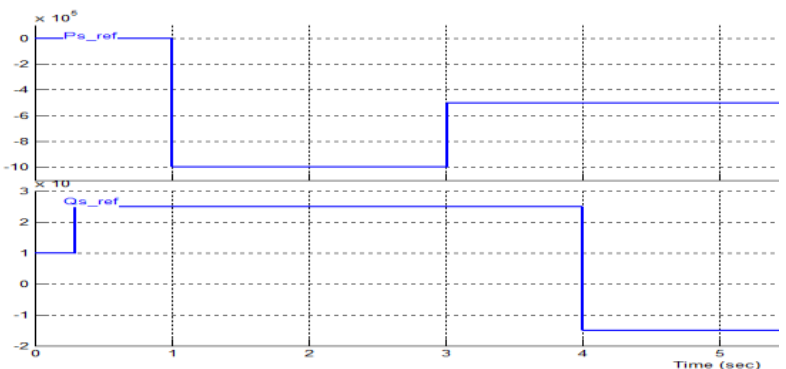

Fig. 8. Waveforms of $P_{s_{-} \text {ref }}$ and $Q_{s_{-} \text {ref }}$.

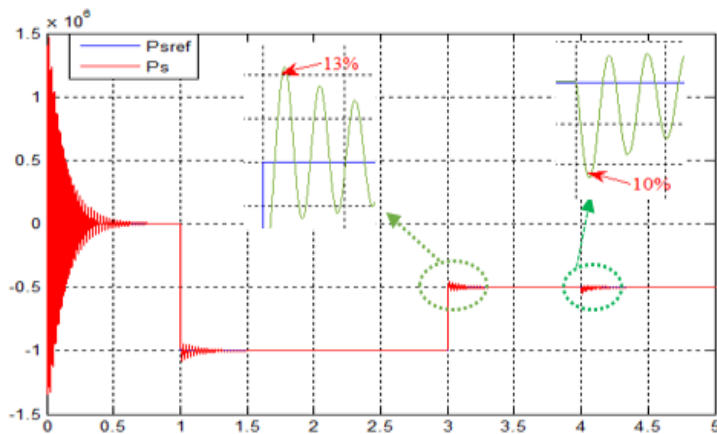

Fig. 9. Active Power Indirect Control (PI)

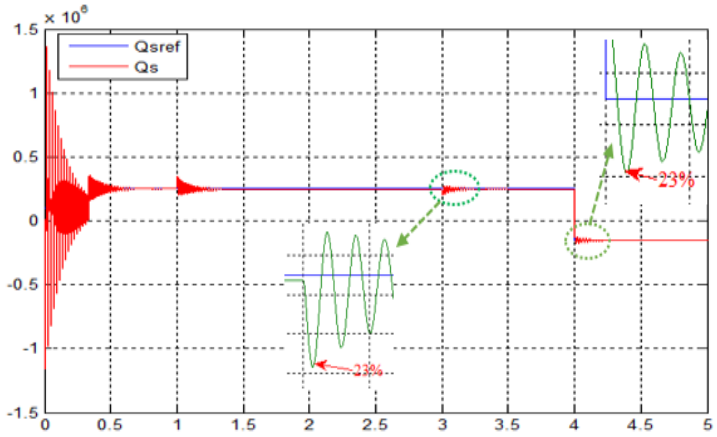

Fig. 10. Reactive Power Indirect Control (PI).

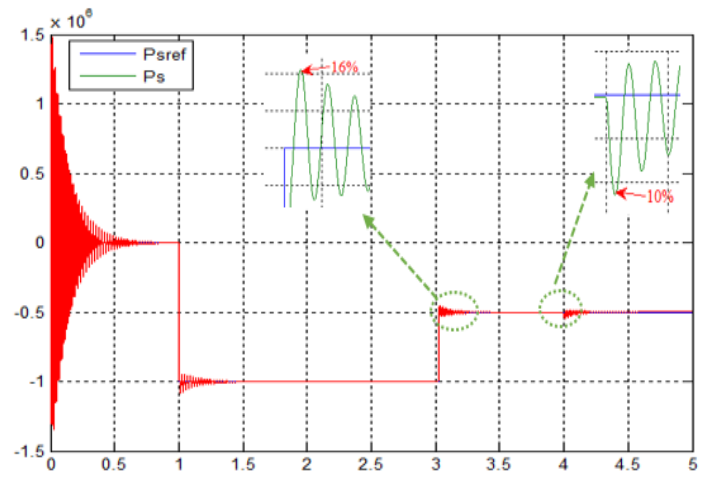

Fig. 11. Active Power Direct Control (PI)

In steady state, there is a sufficient accuracy $\left(0.5 \%\right.$ for $P_{s}$ and $1.2 \%$ for $Q_{s}$, but transient state presents important exceeding rates that we recapitulate in Table I.

We can already issue two important remarks:

- Indirect control approach is better than Direct control in term of exceeding rates.

- Decoupling is not perfect in both strategies and can be worst if parameters vary or are not known with good precision.

TABLE I: COMPARISON OF EXCEEDING RATE D\% BETWEEN DIRECT AND INDIRECT PI CONTROL

\begin{tabular}{|l|c|c|}
\cline { 2 - 3 } \multicolumn{1}{|c|}{} & $\begin{array}{c}\text { PI } \\
\text { Indirect Control }\end{array}$ & $\begin{array}{c}\text { PI } \\
\text { direct Control }\end{array}$ \\
\hline $\begin{array}{l}d \% \text { of Ird } \\
\text { when edge of Qsref }\end{array}$ & $12 \%$ & $20 \%$ \\
\hline $\begin{array}{l}\text { d\% of Ird } \\
\text { when edge of Psref }\end{array}$ & $15 \%$ & $20 \%$ \\
\hline $\begin{array}{l}d \% \text { of Ps } \\
\text { when edge of Psref }\end{array}$ & $13 \%$ & $16 \%$ \\
\hline $\begin{array}{l}d \% \text { of Ps } \\
\text { when edge of Qsref }\end{array}$ & $10 \%$ & $10 \%$ \\
\hline $\begin{array}{l}\text { d\% of Qs } \\
\text { when edge of Qsref }\end{array}$ & $12 \%$ & $13 \%$ \\
\hline $\begin{array}{l}d \% \text { of Qs } \\
\text { when edge of Psref }\end{array}$ & $23 \%$ & $27 \%$ \\
\hline
\end{tabular}

Another main disadvantage of conventional PI controller is its poor capability to deal with system uncertainties which may be caused by external disturbances and parameters variation. Example of robustness against stator inductance variation is given in Fig. 13 where PI can no longer follow the set profiles.



Fig. 12. Reactive Power Direct Control (PI)

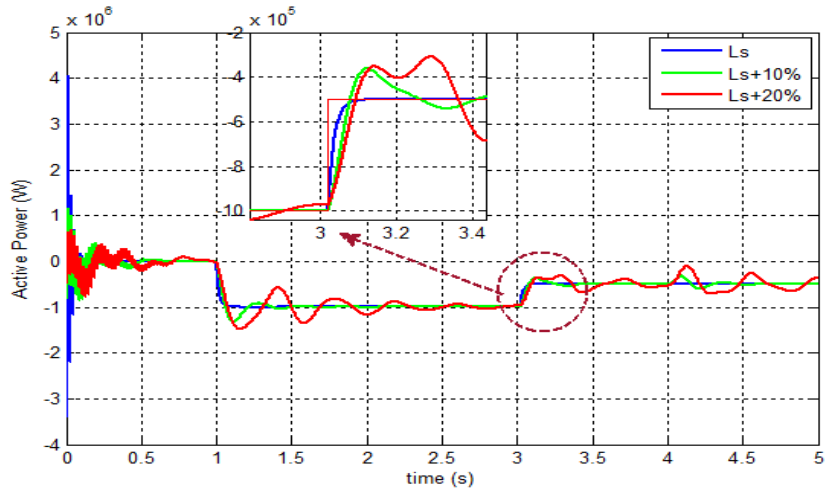

Fig. 13. Robustness of PI Control against Stator Inductance.

\section{CONCLUSION}

The main contribution of this work is to show how to track any references of active and reactive powers dictated by grid codes that are becoming more and more strict because of constant increasing of renewable energies penetration ratio.

Modelling of turbine and associated DFIG are well 
detailed in PQ control purpose. Active and reactive powers are decoupled to can control them in independent way according to dynamic profiles requested by Grid Managers. This modelling constitutes a basis for implementation of any control strategy. In fact, we implemented easily Sliding Mode Controller and confronted results with those of PI. Except the good robustness, SMC presents chattering phenomena that is unacceptable for Medium and high power. Adaptive Sliding Mode Controller (ASCM) is also implemented to reduce this chattering phenomena, but it is very gourmet in computation time like other sophisticated algorithms.

PI controller stays a simple and less costing solution that gives good results in steady state and acceptable performances in transient regime. To remedy to its weak robustness, we are working on making it adaptive by using Particle Swarm Optimization (PSO) algorithm. Combination with Fuzzy logic approach is also expected.

\section{APPENDIX}

DFIG parameters: $S_{N}=3 M V A ; R_{s}=0.012 \Omega ; R_{r}=0.021 \Omega$;

$L_{s}=0.0137 H \quad L_{r}=0.0136 H, M=0.0135 H, p=2, J=0.07 \mathrm{Kg} . m ?$;

$f=0.0024 N \cdot m \cdot s^{-1}$. Turbine parameters: $P_{t N}=4 M W$.

Gear-Boxratio $: G=90$.

\section{REFERENCES}

[1] REN21, "Renewables 2016 global status report," Renewable Energy Policy Network for 21st Century, 2016.

[2] T. G. W. E. Outlook, GWEO, 2012.

[3] ALTERNATIVE ENERGY. (2016). [Online]. Available: www.altenergy.org/renewables/wind

[4] GWEC, Global Wind 2015 Report, April 2016.

[5] R. Babouri, D. Aouzellag, and K. Ghedamsi, "Integration of doubly fed induction generator entirely interfaced with network in a wind energy conversion system," Science Direct, Energy Procedia, vol. 36, pp. 169-178, 2013

[6] F. Poitiers, T. Bouaouiche, and M. Machmoum, "Advanced control of doubly-fed induction generator for wind energy conversion," EPSR, Elsevier, 2009

[7] J. Han, "From PID to active disturbance rejection control," IEEE Transactions on Industrial Electronics, vol. 56, no. 3, March 2009.

[8] A. Boukhriss, T. Nasser, and A. Essadki, "A linear active disturbance rejection control applied for DFIG based wind energy conversion system," IJCSI, vol. 10, no. 2, 2013.

[9] S. Taraft, D. Rékioua, and D. Azoullag, "Commande en mode glissant de la MADA dans une éolienne à vitesse variable connectée au réseau," Revue des Energies Renouvelables SMEE'10 Bou Smaïl Tipaza, 2010.

[10] J. Hu, L. Shang, Y. He, and Z. Zhu, "Direct active and reactive power regulation of grid-connected DC/AC converters using sliding mode control approach," IEEE, 2010.

[11] R. Patnaik, P. Dash, and K. Mahapatra, "Adaptive terminal sliding mode power control of DFIG based wind energy conversion system for stability enhancement," International Transactions on Electrical Energy Systems, John Wiley \& Sons, Ltd, vol. 26, 2016.
[12] S. Abdeddaim and A. Betka, "Optimal Tracking and robust control of the DFIG wind turbine," Electrical Power and Energy Systems, Elsevier, vol. 49, 2013.

[13] S. Ravichandran, R. Kumudinidevi, S. Bharathidasan, and V. E. Jeba, "Coordinated controller design of grid connected DFIG based wind turbine using response surface methodology and NSGA II," Sustainable Energy Technologies and Assessments, Elsevier, vol. 8, 2014.

[14] F. Arama, B. Mazari, A. Dahbi, K. Roummani, and M. Hamouda, "Artificial Intelligence control applied in wind energy system," IEEE, 2014.

[15] A. Pappachen and P. Fathima, "Genetic algorithm based PID controller for two-area deregulated power system along with DFIG unit," ARPN, vol. 10 , no. 9, May 2015 .

[16] A. A. A. Elgammal, "Optimal design of PID controller for doubly-fed induction generator-based wave energy conversion system using milti-objective particle swarm opimization," Journal of Technology Innovations in Renewable Energy, vol. 3, 2014.

[17] S. Hosseini and S. H. Bafghi, "Optimization of direct power control of doubly-fed induction machine (DFIM) using PSO algorithm," IJSEI, vol. 2, 2013.

[18] A. Chemidi, S. M. Meliani, and M. C. Benhabib, "Etude d'une Ferme éolienne à base de MADA connectée au réseau électrique: Analyse et compensation des harmoniques," chez CIGE-2013, Bechar University, 2013.

[19] Grid code for renewable energies, in Proc. Workshop - EMI- Rabat, June 2015.

[20] J.-P. Caron and J.-P. Hautier, Modélisation et Commande de la Machine Asynchrone, Technip, 1995.

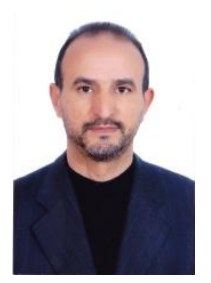

Mbarek Taleb was born in Oujda, Morocco in 1967. He received the engineer degree in electronic and automatic from National High School of Electricity and Mechanics (ENSEM), Nancy, France, in 1991. He received the postgraduate degree (DEA) in acoustic, optoelectronics and structural mechanics from National High School of Mechanics and Microelectronics, Besancon, France in 1993. From 1994 to 2002, he worked in many factories in Morocco. He built up his own company in 2002 that it is running till now. He joined Mohammadia School of Engineers (EMI), Rabat, Morocco in 2014 where he is Ph.D. student in electrical engineering. his current research focuses mainly on Wind Energy Conversion Systems (WECS).

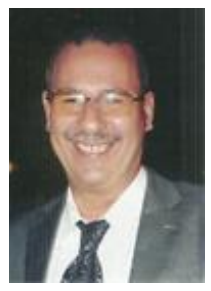

Mohamed Cherkaoui was born in Marrakech, Morocco in 1954. He received the engineer degree in electrical engineering from Mohammadia School of Engineers (EMI), Rabat, Morocco, in 1979. He received his Ph.D. degree in 1990 from Polytechnic National Institute of Lorraine, Nancy, France. He practiced at the beginning of its career as a engineer in Marrakech province where he realized a set of projects of rural electrification. In 1995, he joined Mohammadia School of Engineers (EMI), Rabat, Morocco, where he is a professor and electrical engineering department manager. He is involved in various research projects such as optimization of electrical energy, intelligent systems and renewable energies integration. His main research interests are renewable energy and electrical systems control. 